\title{
BMJ Open Prevalence and health correlates of anaemia among community-dwelling Chinese older adults: the China Health and Retirement Longitudinal Study
}

Ying Wang, ${ }^{1,2}$ Yong-Jing Ping, ${ }^{2}$ Hai-Yu Jin, ${ }^{2}$ Ning Ge, ${ }^{3}$ Chenkai Wu (D) ${ }^{2}$

To cite: Wang Y, Ping Y-J, Jin $\mathrm{H}-\mathrm{Y}$, et al. Prevalence and health correlates of anaemia among community-dwelling Chinese older adults: the China Health and Retirement Longitudinal Study. BMJ Open 2020;10:e038147. doi:10.1136/ bmjopen-2020-038147

- Prepublication history and supplemental materials for this paper is available online. To view these files, please visit the journal online (http://dx.doi org/10.1136/bmjopen-2020038147).

YW and Y-JP contributed equally.

Received 29 February 2020 Revised 13 September 2020 Accepted 01 October 2020

\section{Check for updates}

C Author(s) (or their employer(s)) 2020. Re-use permitted under CC BY-NC. No commercial re-use. See rights and permissions. Published by BMJ.

${ }^{1}$ School of Health Sciences, Wuhan University, Wuhan, Hubei, China

${ }^{2}$ Global Health Research Center, Duke Kunshan University, Kunshan, Jiangsu, China ${ }^{3}$ National Clinical Research Center for Geriatrics, Sichuan University West China Hospital, Chengdu, Sichuan, China

Correspondence to Dr Chenkai Wu; chenkai.wu@dukekunshan. edu.cn

\section{ABSTRACT}

Objectives To identify the prevalence of anaemia among older adults in China by sociodemographic and geographical regions, and cross-sectionally examine the associations between anaemia and several geriatric outcomes.

Design Cross-sectional study.

Setting and participants Participants were 6656 older adults aged at least 60 years with haemoglobin data from the 2015 to 2016 wave of the China Health and Retirement Longitudinal Study.

Methods We examined the prevalence of anaemia by sociodemographics (age, sex, residence, education, marital status) and geographical regions, adjusting for age. We investigated the associations between anaemia and geriatric conditions.

Results The prevalence of anaemia was $20.6 \%$ among adults $\geq 60$ years and was higher at advanced ages, among those who were females, living in rural areas, and those who were unmarried. The southern region of China had a higher burden of anaemia than the north. Anaemic adults had a higher age-adjusted prevalence of falls, activities of daily living (ADL) disability, instrumental ADL disability, lower extremely functional limitation, upper extremely functional limitation, low gait speed, low grip strength and low self-reported memory.

Conclusions Anaemia affected approximately one in five older adults in China, particularly in those with disadvantaged sociodemographics, and anaemia was associated with a higher burden of geriatric conditions Huge geographical disparities of anaemia prevalence between northern and southern regions reflected the dietary variations in different regions. Efforts on preventing anaemia and reducing regional disparities of anaemia were needed to improve older adults' health in China.

\section{BACKGROUND}

Anaemia is a medical syndrome of insufficient haemoglobin or amount of red blood cells. ${ }^{1}{ }^{2}$ In 2013, an estimated $27 \%$ of the world's population had anaemia with developing regions carrying a disproportionately heavy share of the burden. ${ }^{3}$ Over $90 \%$ of anaemia cases occurred in low-income and middle-income countries. ${ }^{3}$ The majority of studies on anaemia have focused on

\section{Strengths and limitations of this study}

- This study was the first to report the prevalence of anaemia and the geographical disparities of anaemia prevalence in China using a nationally representative sample.

- This study was unable to describe the trend of anaemia prevalence over time and the causal relationship between anaemia and geriatric outcomes because a cross-sectional study design was used.

- Interview bias may not be fully prevented.

- Lack of serum iron data in blood tests.

- Self-reported measures may provide underestimated results.

children and women of reproductive age (15-49 years) because anaemia during early childhood and pregnancy led to an array of adverse outcomes including low birth weight, developmental delay and maternal mortality and morbidity. ${ }^{45}$ In contrast, anaemia among older adults-a group that is growing at an unprecedented pace globally-has been studied much less extensively. Findings from US studies have shown that anaemia was prevalent among older adults and associated with disability, decreased physical performance and cognitive decline. ${ }^{2}$ However, very limited investigations have been conducted in less developed regions. Population ageing is a global phenomenon. In 2015, over two-thirds of the world's population aged 60 years or older residing in developing countries. ${ }^{6}$

China has the largest ageing population in the world. The number of adults aged 60 years and over in China is estimated to increase from 209 million in 2015 to 492 million in $2050 .{ }^{6}$ Additionally, the number of oldest old ( $\geq 80$ years) is projected to quadruple from 22.6 million in 2013 to 90.4 million in $2050 .^{7}$ The ageing of the population will increase the number of older adults with anaemia, which could potentially lead to a large increase in 
health expenditures. Ongoing anaemia prevention and treatment programmes in China have focused on children and pregnant women, with little attention given to older adults. A comprehensive picture of the epidemiology of anaemia in China would identify subgroups of Chinese older adults with high anaemia prevalence, provide insights into potential sociodemographic and geographic disparities in anaemia, and enhance our understanding of potential risk factors for, and consequences of, anaemia among Chinese older adults.

\section{OBJECTIVES}

In this study, we used the China Health and Retirement Longitudinal Study (CHARLS), a nationally representative cohort of the community-dwelling Chinese population, to (1) identify the prevalence of anaemia among older adults in China by sociodemographic and geographical regions, and (2) cross-sectionally examine the associations between anaemia and several geriatric outcomes.

\section{METHODS}

\section{Data and study participants}

Data were from the 2015 to 2016 wave of CHARLS, a cohort study comprising a nationally representative sample of middle-aged and older adults from 28 provinces in China. The response rate of $80.5 \%$ produced 17708 Chinese residents aged 45 years or above were enrolled at baseline (2011-2012). Of 19.5\% non-respondents, $8.8 \%$ refused to respond, $8.2 \%$ lost contact with interviewers, and $2.0 \%$ were due to other reasons (eg, residents were incapable of participation because of health-related or interviewrelated reasons). ${ }^{8}$ All participants gave informed consent. Further details about the study design and data quality management have been previously documented. ${ }^{8}$ We only had access to the deidentified data set downloaded from the CHARLS project website (http://charls.pku. edu.cn/en). We used the Strengthening the Reporting of Observational Studies in Epidemiology cross sectional checklist when writing our report. ${ }^{9}$

A total of 6656 adults aged at least 60 years and had data on haemoglobin were included in the present study; older adults with missing data on age, haemoglobin or sampling weight were excluded $(\mathrm{n}=3692)$. Compared with participants included in the analytical sample, those excluded persons were older, slightly more likely to be female, live in rural areas, and have lower education levels, and had worse health conditions (disability, slow gait speed, and grip strength (see online supplemental table S1)).

\section{Patient and public involvement}

This research was done without patient involvement. Patients were not invited to comment on the study design and were not consulted to develop patient-relevant outcomes or interpret the results. Patients were not invited to contribute to the writing or editing of this document for readability or accuracy.

\section{Haemoglobin}

Fasting blood samples were collected by trained nurses in a township hospital or a local office of the China Center for Disease Prevention and Control. We defined anaemia as a haemoglobin level less than $120 \mathrm{~g} / \mathrm{L}$ for women and less than $130 \mathrm{~g} / \mathrm{L}$ for men.

\section{Sociodemographics}

We included basic demographic information such as age (60-64, 65-69, 70-74, 75-79 and 80+ years) and sex (male or female). Residence (rural or urban) was recorded based on the types of respondents' locations according to the standardised classification from the National Bureau of Statistics (downtown, rural-urban fringe, town centres, rural-town fringe, special areas, rural centre and village). Participants living in rural centres and villages were merged into the rural category and the rest residence types were classified into the urban category. Education was categorised by the respondents' highest education level (illiterate, can read, elementary school, middle school and high school or above). Marital status was classified into two categories (married/living together vs others) due to the small sample sizes of separated, divorced, widowed and never married categories. Body mass index (BMI) $\left(\mathrm{kg} / \mathrm{m}^{2}\right)$ was calculated as body weight $(\mathrm{kg})$ divided by standing height $(\mathrm{m})$ squared and classified into underweight (BMI $<18.5$ ), normal weight (BMI 18.5-23.9), overweight (BMI 24.0-27.9) and obese (BMI $\geq 28.0$ ). Geographical regions were classified into nine regions (Northwest, Northern, Southwest, Southcentral, East, Central, South, Northeast, Southeast) according to the locations of 28 provinces in China and the urbanisation rate of each region was $50.4 \%, 61.9 \%, 49.4 \%, 54.7 \%$, $72.4 \%, 53.4 \%, 62.7 \%, 61.7 \%$ and $65.6 \%$ in 2016 , respectively (see online supplemental table S2).

\section{Geriatric outcomes}

General health (excellent, very good, good, fair or poor), memory, falls in the previous year were self-reported. Selfreported memory was measured using the question, 'How would you rate your memory at present?' There were five possible responses: excellent, very good, good, fair, or poor. Disability in activities of daily living (ADL; dressing, bathing, eating, getting into or out of bed and toileting) and instrumental ADL (IADL; preparing hot meals, doing household chores, shopping, managing assets and taking medication) were self-reported. Participants were asked, 'Do you have any difficulty in performing the task?'. Those who answered, 'I have difficulty but can still do it', 'Yes, I have difficulty and need help', or 'I cannot do it' were considered as ADL/IADL disability. Usual gait speed was assessed by using the average of two-timed talk tests over a 2.5-m course. Low gait speed was defined as a usual gait speed $<0.6 \mathrm{~m} / \mathrm{s}$ for both men and women. ${ }^{10}$ Grip strength was measured as the maximum of four readings 
(two for each hand) by a handheld dynamometer. Weak grip strength was defined as $<26 \mathrm{~kg}$ for men and $<16 \mathrm{~kg}$ for women. ${ }^{11}$

\section{Statistical analysis}

We estimated the prevalence of anaemia in the overall sample and by demographics including age, sex, residence location, education, marital status, BMI and geographical region. We used the $\chi^{2}$ test to examine the association of each demographic characteristic with anaemia. We identified the prevalence of anaemia by geographical regions, adjusting for age using multinomial logistic regression. Age-adjusted prevalence was estimated at the overall mean age (68 years old). Predicted prevalence was estimated at the weighted mean age in each region. We used multivariable logistic regression to assess the associations between demographics and anaemia.

We identified the relative frequency of falls, disability, functional limitation, gait speed, grip strength, self-rated general health and self-rated memory by anaemia status (yes or no). We used logistic regression to determine each association, adjusting for age. We accounted for the multistage probability sampling design of the CHARLS by specifying the sampling weight (correcting for nonresponse and sampling-frame errors) and primary sampling unit parameters. All tests were two sided with a significance level of $\mathrm{p}<0.05$. Analyses were performed using Stata V.15.0.

\section{RESULTS}

\section{Prevalence of anaemia}

The prevalence of anaemia was $20.6 \%$ (95\% CI $19.4 \%$ to 21.9\%) among Chinese adults aged $\geq 60$ years (table 1 ). The prevalence of anaemia increased steeply with age. Less than $15 \%$ of persons aged 60-64 years had anaemia, while over one-third of those aged $\geq 80$ years had anaemia. We observed a higher prevalence of anaemia among older adults who were women, lived in rural areas, had a lower level of education, and were not married. Approximately $27 \%$ of persons with no formal education had anaemia, whereas slightly over $10 \%$ of persons with at least a high school diploma had anaemia. The prevalence of anaemia was hugely different among older adults in different BMI categories. The prevalence of anaemia was $40.1 \%$, $25.6 \%, 13.3 \%$ and $8.0 \%$ among underweight, normal weight, overweight and obese older adults, respectively. In the multivariable logistic regression model, older age, female, lower education level and lower BMI persisted to be associated with higher odds of anaemia (table 2). There was a substantial geographical variation in anaemia prevalence among older adults in China (figure 1). The prevalence of anaemia ranged from approximately fourfold from $8.5 \%$ in the Northeast region to $35.4 \%$ in the Southcentral region.

\section{Associations between anaemia and geriatric outcomes}

After adjustment for age, the prevalence of falls was significantly higher among older adults with anaemia
Table 1 Prevalence of anaemia by sociodemographics among 6656 adults age $\geq 60$ years from the China Health and Retirement Longitudinal Study, 2015

\begin{tabular}{|c|c|c|}
\hline & $\begin{array}{l}\text { Demographic } \\
\text { characteristics of } \\
\text { the sample (\%) }\end{array}$ & $\begin{array}{l}\text { Prevalence of } \\
\text { anaemia \% } \\
(95 \% \mathrm{Cl})\end{array}$ \\
\hline Total & & 20.6 (19.4 to 21.9$)$ \\
\hline \multicolumn{3}{|l|}{ Age, years ${ }^{\star \star \star}$} \\
\hline $60-64$ & 36.3 & $14.9(13.3$ to 16.7$)$ \\
\hline $65-69$ & 27.9 & $17.4(15.4$ to 19.7$)$ \\
\hline $70-74$ & 18.1 & 23.0 (20.2 to 26.2$)$ \\
\hline $75-79$ & 10.8 & 30.5 (26.1 to 35.2$)$ \\
\hline $80+$ & 6.8 & 36.0 (30.3 to 42.0$)$ \\
\hline \multicolumn{3}{|l|}{$\operatorname{Sex}{ }^{* * *}$} \\
\hline Male & 49.5 & 18.5 (16.8 to 20.2$)$ \\
\hline Female & 50.5 & 22.8 (21.0 to 24.6$)$ \\
\hline \multicolumn{3}{|l|}{ Residence ${ }^{\star \star \star}$} \\
\hline Rural & 75.7 & 24.7 (23.3 to 26.1$)$ \\
\hline Urban & 24.1 & 13.8 (11.9 to 16.0$)$ \\
\hline \multicolumn{3}{|l|}{ 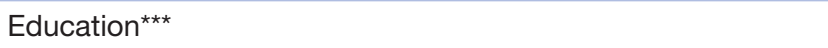 } \\
\hline Illiterate & 29.7 & $28.2(25.8$ to 30.7$)$ \\
\hline Can read & 29.3 & 21.5 (19.3 to 24.0$)$ \\
\hline Elementary school & 22.4 & 19.5 (17.0 to 22.2$)$ \\
\hline Middle school & 12.6 & $14.4(11.9$ to 17.3$)$ \\
\hline $\begin{array}{l}\text { High school or } \\
\text { above }\end{array}$ & 5.4 & 9.2 (6.0 to 13.9$)$ \\
\hline \multicolumn{3}{|l|}{ Marital status ${ }^{\star \star \star}$} \\
\hline $\begin{array}{l}\text { Married/living } \\
\text { together }\end{array}$ & 79.8 & 18.8 (17.5 to 20.2$)$ \\
\hline Others & 20.2 & 27.2 (24.2 to 30.3$)$ \\
\hline \multicolumn{3}{|c|}{ Body mass index, $\mathrm{kg} / \mathrm{m}^{2 \star \star \star}$} \\
\hline$<18.5$ & 7.5 & 40.1 (35.3 to 45.2 ) \\
\hline $18.5-23.9$ & 48.9 & 25.6 (23.7 to 27.5$)$ \\
\hline $24.0-27.9$ & 29.3 & $13.3(11.5$ to 15.2$)$ \\
\hline$\geq 28.0$ & 13 & 8.0 (6.1 to 10.6$)$ \\
\hline
\end{tabular}

The number of participants is unweighted. Percentage estimates are weighted. $P$ values were obtained by t-test for continuous variables and $\chi^{2}$ test for categorical variables.

${ }^{*} \mathrm{P}<0.05,{ }^{* *} \mathrm{p}<0.01,{ }^{* \star *} \mathrm{p}<0.001$, for comparing prevalence of anaemia by each factor.

than those without $(22.6 \%$ vs $17.5 \%$, table 3$)$. Anaemic older adults had a significantly higher age-adjusted prevalence of disability and functional limitation than those who were not anaemic. We also observed that older adults with anaemia had a higher prevalence of slow gait speed than those without $(18.3 \%$ vs $15.2 \%)$. Similar results were observed among elders with weak grip strength compared with those without (12.5\% vs $8.8 \%)$. Nearly $40 \%$ of anaemic older adults reported poor memory, while only approximately one-third of non-anaemic older adults had poor memory. Non-anaemic older adults had 
Table 2 Logistic regression results of the associations between social-demographic factors and anaemia among older adults

\begin{tabular}{|c|c|c|}
\hline \multirow[b]{2}{*}{ Socialdemographic factors } & \multicolumn{2}{|l|}{ Anaemia } \\
\hline & OR $(95 \% \mathrm{Cl})$ & P value \\
\hline \multicolumn{3}{|l|}{ Age, years } \\
\hline $60-64$ & Ref. & Ref. \\
\hline $65-69$ & 1.21 (1.03 to 1.42$)$ & 0.024 \\
\hline $70-74$ & 1.62 (1.36 to 1.93$)$ & $<0.001$ \\
\hline $75-79$ & 2.06 (1.67 to 2.53$)$ & $<0.001$ \\
\hline $80+$ & 2.29 (1.79 to 2.94$)$ & $<0.001$ \\
\hline Female versus male & 1.32 (1.16 to 1.52$)$ & $<0.001$ \\
\hline Urban versus rural & 0.86 (0.73 to 1.01$)$ & 0.058 \\
\hline \multicolumn{3}{|l|}{ Education } \\
\hline Illiterate & Ref. & Ref. \\
\hline Can read & 0.94 (0.80 to 1.10$)$ & 0.429 \\
\hline Elementary school & 0.91 (0.75 to 1.09$)$ & 0.297 \\
\hline Middle school & 0.74 (0.58 to 0.94$)$ & 0.013 \\
\hline High school or above & 0.53 (0.37 to 0.77$)$ & 0.001 \\
\hline Married versus other & 0.93 (0.79 to 1.08$)$ & 0.333 \\
\hline \multicolumn{3}{|l|}{ Body mass index, $\mathrm{kg} / \mathrm{m}^{2}$} \\
\hline$<18.5$ & Ref. & Ref. \\
\hline $18.5-23.9$ & 0.66 (0.54 to 0.81$)$ & $<0.001$ \\
\hline $24.0-27.9$ & 0.37 (0.29 to 0.46$)$ & $<0.001$ \\
\hline$\geq 28$ & 0.22 (0.17 to 0.31$)$ & $<0.001$ \\
\hline
\end{tabular}

$P$ values were obtained by the logistic regression analysis for all variables.

similar self-reported health compared with anaemic older adults $(54.6 \%$ vs $50.0 \%)$.

\section{DISCUSSION}

In this large, nationally representative sample of Chinese older adults, we found that $20.6 \%$ of Chinese adults aged 60 years or over had anaemia. We observed a higher prevalence of anaemia at older ages and among those who were females, lived in rural areas and were less educated. We also observed substantial geographical heterogeneity and rural-urban disparities in the prevalence of anaemia in China. Besides, we found that older persons who were anaemic had the excessive burden of adverse geriatric outcomes, even after adjustment for chronological age.

We found that approximately one in five Chinese older adults had anaemia. Our findings were in line with previous studies conducted in developed countries, showing that the prevalence of anaemia was higher at older ages, among females, persons with unfavourable socioeconomic status and in lower BMI groups. ${ }^{12}$ For example, data from the National Health and Nutrition Examination Surveys conducted in the USA showed that the prevalence of anaemia is higher among 70-79 and $80-85$ age groups and females. ${ }^{12}$ A cross-sectional study conducted in Poland revealed that the prevalence of anaemia was higher among older adults living in unmarried status and with a lower level of education. ${ }^{13}$

We observed substantial geographical disparities in the prevalence of anaemia among Chinese older adults. The prevalence of anaemia was almost threefold higher in rural than in urban areas. Older adults living in southcentral and southwest areas $(35.4 \%$ and $29.3 \%$, respectively) had a higher prevalence of anaemia than those residing in east, southeast and northern regions $(22.4 \%, 16.8 \%$ and $8.9 \%$, respectively). There are some plausible explanations for these regional differences. First, a slow economic growth rate may contribute to insufficient expenditures in healthcare services in the central and western regions of China. Older adults living in these areas may adopt an unbalanced diet due to a lack of health information and financial resources, which may lead to nutritional deficiency and, in turn, an increase in the prevalence of anaemia. ${ }^{14}$ Second, personnel shortages in the healthcare system may result in poor delivery of health services to the ageing population and lead to a high burden of non-communicable and infectious diseases in central and west regions of China. ${ }^{14}$ We also observed that older adults living in the south had a substantially higher prevalence of anaemia than those living in the north. Different dietary patterns between individuals living in the south and north part of China may, at least partially, explain this huge difference. Data from the China Health and Nutrition Survey showed that the serum ferritin concentrations among persons living in northern regions were higher than those living in the south. ${ }^{15}$ Iron deficiency has been well established as a strong risk factor of anaemia and serum ferritin concentrations. ${ }^{15}$ Red meat was the primary contributor to the absorption of heme-iron in China. ${ }^{16}$ Therefore, older adults living in northern regions of China may have high red meat consumption, leading to a low prevalence of anaemia. The northsouth disparities in the prevalence of anaemia highlighted the importance of taking in an adequate amount of ironsufficient food or dietary supplements among older adults to prevent anaemia.

We found that Chinese older adults with anaemia had a higher burden of adverse geriatric outcomes, including disability, functional limitation, slow gait speed, low grip strength and poor self-rated memory than those without anaemia. ${ }^{2}$ These results were echoed by Ruan et al's study in which anaemia was found to be associated with frailty. ${ }^{17}$ A cohort study conducted in the USA showed that anaemia was associated with a high risk of dementia among adults aged 70 years or above. ${ }^{2}$ Additionally, a cross-sectional study conducted in Europe demonstrated that older adults with anaemia had a higher prevalence of decreased renal function and functional iron deficiency than those without. ${ }^{18}$ Indeed, anaemia was often of reciprocal causation with medical conditions in older patients such as chronic kidney disease, malnutrition and cardiovascular disease ${ }^{1920}$ Overall, anaemia evolving with function decline of the immune system, metabolism and 


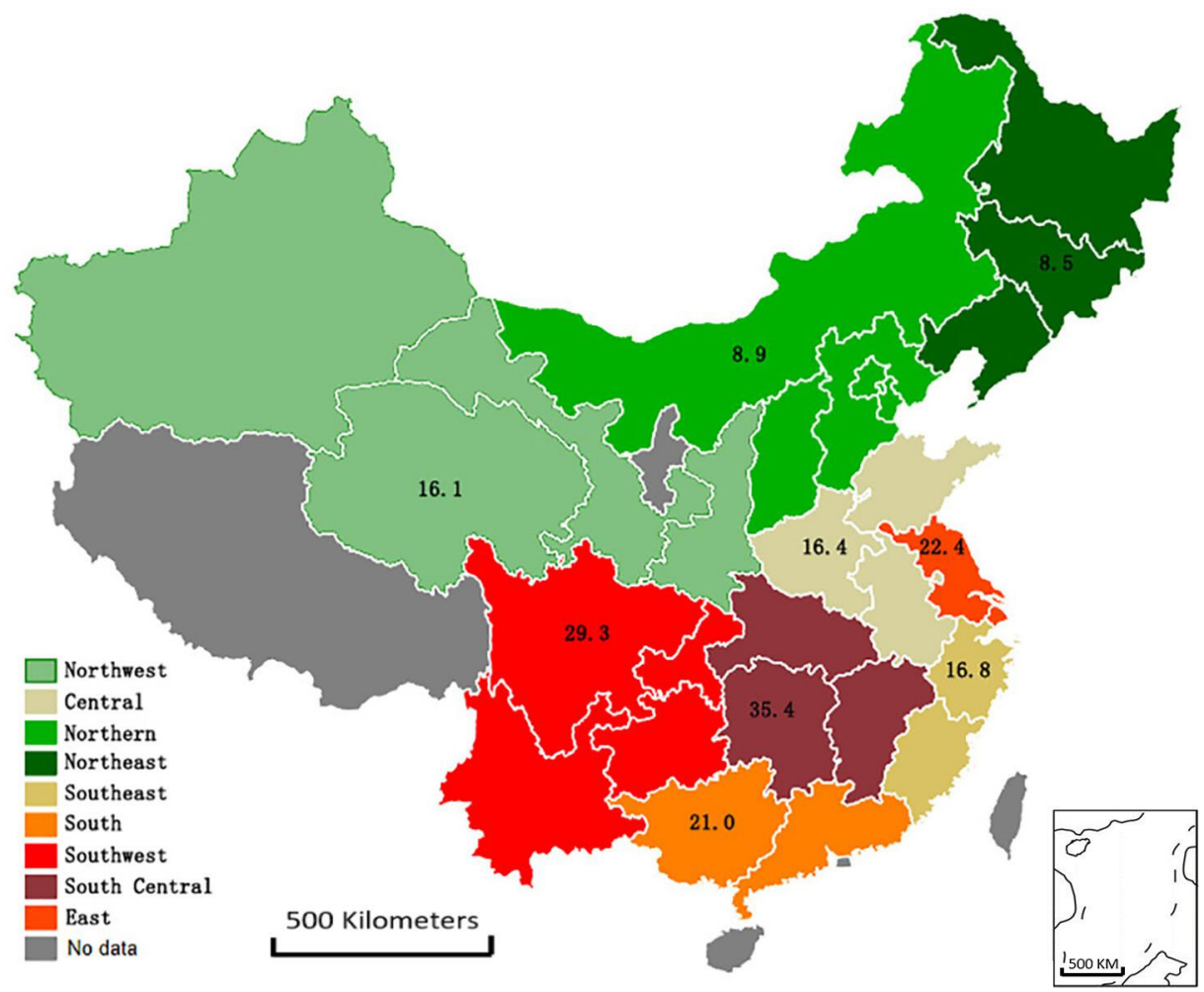

Figure 1 Age-adjusted prevalence of anaemia among adults aged $\geq 60$ years by districts. Weighted prevalence was estimated at the weighted median age in each district.

neurological system accelerated vulnerability to adverse clinical outcomes in the older population. ${ }^{21}$

Our study has several strengths. First, we are among the first to report the prevalence of anaemia in China using a nationally representative sample. A national anaemia screening among older adults would provide thorough surveillance for older adults to reduce mortality and the risk of comorbidity and disability and improve the allocation of healthcare resources and nutritional supplementation. Moreover, nationwide anaemia surveillance would identify subgroups of Chinese older adults with a high burden of anaemia, enhance our understanding of potential risk factors, and implicate other developing countries to take action to monitor and detect the anaemia status among older adults. Second, this study is among the first to reveal the geographical disparities of anaemia prevalence in China. These regional disparities are not fully explained by unbalanced economic development and the distributions of healthcare resources. Dietary patterns such as a high amount of iron-sufficient food could also contribute to the geographical disparities of anaemia prevalence in China. Efforts on reducing anaemia prevalence in China such as providing dietary health education should be tailored to older adults and focus on vulnerable groups. We acknowledged some limitations. First, we were unable to describe the trend of anaemia prevalence over time or illustrate the causal relationship between anaemia and geriatric outcomes because we used a cross-sectional study design. Second, interview bias may not be completely avoided. However, this bias is not likely to be severe because all interviewers had been rigorously trained at Peking University by CHARLS staff members, and the computer-assisted person interviewing technology was used. Third, we may not distinguish irondeficiency anaemia from general anaemia because the CHARLS did not test the concentration of serum iron. Finally, self-reported health measures might provide underestimated results because participants had relatively better health conditions and more positive survival expectations. These self-reported health measures were still considered to be reliable because these measures have been used extensively and provided consistent results in previous research. ${ }^{22}$

In conclusion, approximately one in five older adults in China had anaemia and substantial sociodemographic and regional disparities exist. We also revealed that older adults with anaemia had a higher burden of geriatric outcomes than those without. Besides, we observed a huge geographical disparities of anaemia prevalence in China. This work suggests that early screening and intervention are important for preventing or postponing the occurrence of poor outcomes and maintaining high life quality. The study findings could also contribute to a better understanding of China's growing regional disparities in healthcare resources and highlight the importance of prevention for and treatment of anaemia among the older population. Given the paucity of data on anaemia among Chinese older adults, our findings are critical for further research aimed at determining the causal relation between anaemia and health outcomes and identifying 
Table 3 Age-adjusted prevalence of health events, disability and functional limitation by anaemia among adults ages $\geq 60$ years

\begin{tabular}{|c|c|c|}
\hline & Anaemia & Non-anaemia \\
\hline & $\%(95 \% \mathrm{Cl})$ & $\%(95 \% \mathrm{Cl})$ \\
\hline $\begin{array}{l}\text { Falls in previous } \\
\text { year }\end{array}$ & 22.6 (19.8 to 25.4$)$ & 17.5 (16.0 to 18.9$)$ \\
\hline ADL disability ${ }^{\star \star}$ & 23.7 (21.1 to 26.3$)$ & 20.3 (18.7 to 21.9$)$ \\
\hline IADL disability*** & $29.0(26.2$ to 31.8$)$ & 23.7 (21.8 to 25.6$)$ \\
\hline $\begin{array}{l}\text { Lower extremity } \\
\text { functional } \\
\text { limitation }^{\star \star \star}\end{array}$ & 62.2 (59.0 to 65.5$)$ & 59.3 (57.1 to 61.4$)$ \\
\hline $\begin{array}{l}\text { Upper extremity } \\
\text { functional } \\
\text { limitation*** }\end{array}$ & 26.7 (23.9 to 29.5$)$ & 22.4 (20.7 to 24.2$)$ \\
\hline Slow gait speed $\dagger,{ }^{\star \star \star}$ & 18.3 (15.9 to 20.7 ) & 15.2 (13.8 to 16.5$)$ \\
\hline $\begin{array}{l}\text { Low grip } \\
\text { strength } \neq,{ }^{* * *}\end{array}$ & 12.5 (10.5 to 14.5$)$ & $8.8(7.5$ to 10.1$)$ \\
\hline \multicolumn{3}{|c|}{ Self-rated general health ${ }^{\star \star \star}$} \\
\hline Good and above & 16.1 (13.6 to 18.7$)$ & 20.2 (18.7 to 21.7$)$ \\
\hline Fair & 50.0 (46.8 to 53.2$)$ & 54.6 (52.4 to 56.8$)$ \\
\hline Poor and below & 33.9 (30.9 to 36.9$)$ & 25.2 (23.4 to 27.0$)$ \\
\hline \multicolumn{3}{|l|}{ Self-rated memory ${ }^{\star \star \star}$} \\
\hline Good and above & 12.9 (10.5 to 15.3$)$ & 14.0 (12.2 to 15.9$)$ \\
\hline Fair & $47.8(44.6$ to 51.1$)$ & 52.9 (50.6 to 55.2$)$ \\
\hline Poor & 39.3 (36.1 to 42.4 ) & 33.1 (31.0 to 35.2 ) \\
\hline
\end{tabular}

Age-adjusted prevalence was estimated at the overall mean age (68 years old). Predicted prevalence was estimated at the weighted mean age in each region.

${ }^{*} \mathrm{P}<0.05,{ }^{*} \mathrm{P}<0.01$, ${ }^{\star *} \mathrm{P}<0.001$ for comparing prevalence of anaemia by each factor.

†Slow gait speed: $<0.6 \mathrm{~m} / \mathrm{s}$.

łLow grip strength: $<16 \mathrm{~kg}$ for female and $<26 \mathrm{~kg}$ for male. $A D L$, activities of daily living; IADL, instrumental activities of daily living.

physiological, psychological and social risk factors of anaemia in China.

Contributors YW, Y-JP and CW conceived and designed the study. YW, Y-JP, H-YJ and $N G$ analysed and interpreted the data. NG provided clinical expertise. YW, Y-JP and CW drafted the manuscript. All authors critically revised the manuscript.

Funding This work was supported by the Ministry of Science and Technology in China (2020YFC2005600) and the Suzhou Municipal Science and Technology Bureau (SS2019069). The research results of this article are sponsored partly by the Kunshan Municipal Government research funding.

Disclaimer The funder played no role in study design, data collection, and analysis, the decision to publish, or preparation of the manuscript.

Map disclaimer The depiction of boundaries on the map(s) in this article does not imply the expression of any opinion whatsoever on the part of BMJ (or any member of its group) concerning the legal status of any country, territory, jurisdiction or area or of its authorities. The map(s) are provided without any warranty of any kind either express or implied.

Competing interests CW provides paid consultant services to HealthKeeperS, a startup health data analytics company in China. Other authors have no conflict of interest to disclose.

Patient consent for publication Not required.
Ethics approval The protocol was approved by the Ethical Review Committee at Peking University. The present study was exempt from requiring ethical approval from the Institutional Review Board at Duke Kunshan University because we only involved secondary data analysis of persons who consented to participate in the CHARLS.

Provenance and peer review Not commissioned; externally peer reviewed.

Data availability statement Data used in the present study are freely accesible at: http://charls.pku.edu.cn/index/en.html

Supplemental material This content has been supplied by the author(s). It has not been vetted by BMJ Publishing Group Limited (BMJ) and may not have been peer-reviewed. Any opinions or recommendations discussed are solely those of the author(s) and are not endorsed by BMJ. BMJ disclaims all liability and responsibility arising from any reliance placed on the content. Where the content includes any translated material, BMJ does not warrant the accuracy and reliability of the translations (including but not limited to local regulations, clinical guidelines, terminology, drug names and drug dosages), and is not responsible for any error and/or omissions arising from translation and adaptation or otherwise.

Open access This is an open access article distributed in accordance with the Creative Commons Attribution Non Commercial (CC BY-NC 4.0) license, which permits others to distribute, remix, adapt, build upon this work non-commercially, and license their derivative works on different terms, provided the original work is properly cited, appropriate credit is given, any changes made indicated, and the use is non-commercial. See: http://creativecommons.org/licenses/by-nc/4.0/.

ORCID iD

Chenkai Wu http://orcid.org/0000-0002-0072-694X

\section{REFERENCES}

1 Beghé C, Wilson A, Ershler WB. Prevalence and outcomes of anemia in geriatrics: a systematic review of the literature. Am J Med 2004;116:3-10.

2 Hong $\mathrm{CH}$, Falvey $\mathrm{C}$, Harris TB, et al. Anemia and risk of dementia in older adults: findings from the health $A B C$ study. Neurology 2013;81:528-33.

3 Kassebaum NJ. The global burden of anemia. Hematol Oncol Clin North Am 2016;30:247-308.

4 Chen M-H, Su T-P, Chen Y-S, et al. Association between psychiatric disorders and iron deficiency anemia among children and adolescents: a nationwide population-based study. BMC Psychiatry 2013;13:161.

5 Daru J, Zamora J, Fernández-Félix BM, et al. Risk of maternal mortality in women with severe anaemia during pregnancy and post partum: a multilevel analysis. Lancet Glob Health 2018;6:e548-54.

6 United Nations, Department of Economic and Social Affairs, Population Division. World population prospects: the 2012 revision, highlights and advance tables. ESA/P/WP.228, 2013

7 United Nations, Department of Economic and Social Affairs, Population Division. World population prospects: the 2015 revision, key findings and advance tables. ESA/P/WP.241, 2015

8 Zhao Y, Hu Y, Smith JP, et al. Cohort profile: the China health and retirement longitudinal study (CHARLS). Int $J$ Epidemiol 2014;43:61-8.

9 von Elm E, Altman DG, Egger M, et al. The strengthening the reporting of observational studies in epidemiology (STROBE) statement: guidelines for reporting observational studies. Ann Intern Med 2007:147:573-7.

10 Chen L-K, Liu L-K, Woo J, et al. Sarcopenia in Asia: consensus report of the Asian working group for sarcopenia. J Am Med Dir Assoc 2014:15:95-101.

11 Alley DE, Shardell MD, Peters KW, et al. Grip strength cutpoints for the identification of clinically relevant weakness. J Gerontol A Biol Sci Med Sci 2014;69:559-66.

$12 \mathrm{Le} \mathrm{CHH}$. The prevalence of anemia and moderate-severe anemia in the US population (NHANES 2003-2012). PLoS One 2016;11:e0166635.

13 Styszynski A, Mossakowska M, Chudek J, et al. Prevalence of anemia in relation to socio-economic factors in elderly Polish population: the results of PolSenior study. J Physiol Pharmacol 2018;69:75-81.

14 Fang P, Dong S, Xiao J, et al. Regional inequality in health and its determinants: evidence from China. Health Policy 2010;94:14-25.

$15 \mathrm{Hu}$ PJ, Ley SH, Bhupathiraju SN, et al. Associations of dietary, lifestyle, and sociodemographic factors with iron status in Chinese 
adults: a cross-sectional study in the China health and nutrition survey. Am J Clin Nutr 2017;105:503-12.

16 Ortega DL, Holly Wang H, Eales JS. Meat demand in China. China Agricultural Economic Review 2009;1:410-9.

17 Ruan Y, Guo Y, Kowal P, et al. Association between anemia and frailty in 13,175 community-dwelling adults aged 50 years and older in China. BMC Geriatr 2019;19:327.

18 Bach V, Schruckmayer G, Sam I, et al. Prevalence and possible causes of anemia in the elderly: a cross-sectional analysis of a large European university hospital cohort. Clin Interv Aging 2014;9:1187.

19 Ezekowitz JA, McAlister FA, Armstrong PW. Anemia is common in heart failure and is associated with poor outcomes: insights from a cohort of 12065 patients with new-onset heart failure. Circulation 2003:107:223-5.

20 Go AS, Yang J, Ackerson LM, et al. Hemoglobin level, chronic kidney disease, and the risks of death and hospitalization in adults with chronic heart failure: the anemia in chronic heart failure: outcomes and resource utilization (anchor) study. Circulation 2006;113:2713-23.

21 Wang CQ, Udupa KB, Lipschitz DA. Interferon-Gamma exerts its negative regulatory effect primarily on the earliest stages of murine erythroid progenitor cell development. J Cell Physiol 1995;162:134-8.

22 Lei X, Sun X, Strauss J, et al. Health outcomes and socio-economic status among the mid-aged and elderly in China: evidence from the CHARLS national baseline data. J Econ Ageing 2014;4:29-43. 